\title{
Wait for Time to Heal a Severely Battered Image: Positing Perception Management in Higher and Tertiary Institutions in Zimbabwe
}

\author{
Nyenya Trust \\ Zimbabwe Open University \\ Mashonaland East Region, Marondera \\ Zimbabwe \\ nyenyat@gmail.com
}

\author{
Mukungurutse Sarah Yeukai \\ Zimbabwe Open University \\ Mashonaland East Region, Marondera, \\ Zimbabwe \\ sarahyeukai@gmail.com
}

\begin{abstract}
Against a backdrop of negative publicity, some universities in Zimbabwe have struggled to maintain their image with difficulty. Little or no effort has been made by these institutions to spruce up their image except to respond to allegations in the press. This study was a survey carried out in order to establish the applicability, or otherwise, of perception management in higher and tertiary institutions. The paper sought to find out whether the universities were aware of perception management. The study further sought to justify that action is needed to save a battered image. The qualitative paradigm was employed and the descriptive survey was used to discover the adaptability of perception management in institutions of higher learning. Interviews were used in collecting data from university lecturers from five selected universities in Zimbabwe with a total of 920 lecturers. A purposive sample of $45(5 \%)$ lecturers was used in this study. The results of this study revealed the lecturers were not aware of perception management. All universities in Zimbabwe do not have perception management units. The study therefore recommends that organisations have awareness workshops on perception management. Lastly the study recommends that universities should be proactive in improving their images. Either the universities make effective use of the Public Relations office in perception management or they create a perception management unit that works all year round to enhance their image.
\end{abstract}

Keywords: Perception management, image, higher and tertiary institutions

\section{INTRODUCTION}

Some Universities in Zimbabwe have faced intense negative publicity ranging from student moral decadence to credibility of degree programmes among a host of other negativities. It is expected that providing positive information and publicity improve the perception of the organisations. Otara (2011:21) contends that, "objective perception is difficult if not impossible and as such, unmanaged perceptions become a reality that was not intended that becomes the image" of the organisation. Elsbach (2006:12) defines organisational perception management (OPM) as "actions that are designed and carried out by organisational spokespersons to influence audiences' perceptions of the organisation." These actions, in perception management should be done before, during and after an event that either threatens or enhances the image of an organisation as Elsbach asserts.

Oftentimes higher educational institutions (HEIs) have remained mum about it waiting for time to heal the battered image. Benoit (1995) acknowledges that silence is a tactic that can be used in organisational crisis events. However, Rogers, Dillard, and Yuthas, (2005) and Trinkaus and Giacolone, (2005) contend that in crisis management, silence impacts negative perception. In some instances, the recovery has been very slow due to lack of image repair through organisational perception management (OPM) which may help to improve or protect the organisation perception. If HEIs do not manage their perceptions the unintended image becomes a reality thereby making it difficult for them to get the needed support through improved student enrolments and funding for various projects from private sources.

Zimbabwe Open University (ZOU) had its Diploma in Primary programmes not recognized by the Public Service Commission. The Herald 16 September 2012 ran an article headed "Z.O.U. teaching diploma useless-public service commission." The report indicated that the Public Service Commission did not recognize the teaching diploma thereby damaging the image of the institution. There was a lot 
of media coverage on the issue resulting in the university image being so low. This move also impacted greatly on the enrolment, as there was a large decline in student enrolment. Midlands State University was in the media for moral decay of its students. Instead of the university being an institution of learning it became a hub of prostitution and moral decay as was stated in the papers. The Eye 2013 reports that, "the Gweru-based higher learning institution is also dubbed Midlands Sex University (MSU) by some quarters due to countless number of sex tapes and sex scandals the university's students have produced. MSU students are notorious for a number of shenanigans, pornography, wild sex, cohabiting and drugs among other vices." Very little effort was made to salvage its image as if the institution condones such vices. Solusi University was also in the press for the wrong reasons. There were accusations on the conduct of its management on labour issues. Its efforts were hardly recognizable in protecting its image.

\section{Statement of the Problem}

While perception management has been used in the military for quite some time now with significant gains, HEIs have been slow in using the concept to improve their image casting doubt on its applicability in this area. The overarching question this study seeks to answer is; How applicable is the concept of perception management to HEIs?

\section{RESEARCH QUESTIONS}

This study seeks to find answers to the following questions:

1. What is the level of academics awareness of organisational perception management?

2. Which organisational perception management goals would be suitable for HEIs?

3. How would HEIs perform organisational perception management?

4. When are organisational perception management activities carried out?

\section{ObJectives Of The Study}

The study was carried out under the following objectives:

- Assess the academics' level of awareness of organisational perception management.

- Explain organisational perception management goals for HEIs.

- Identify organisational perception management tactics applicable to HEIs

- Explore the timing of organisational perception management activities.

\section{RESEARCH METHOdOLOGY}

This study adopted the qualitative approach method and the descriptive survey was used to discover the adaptability of perception management in institutions of higher learning. Interviews were used in collecting data from 45 university lecturers from five selected universities in Zimbabwe. Purposive sampling was used where five universities in Zimbabwe were selected out of the fifteen accredited universities. The selected universities were those, which had negative reports in the media. The snowballing technique was used to identify academics who participated in the research. The lecturers were from the universities with negative media reports. Findings were analyzed in themes. The findings were narrated and discussed also in themes.

\section{Literature REVIEW}

\subsection{Defining Perception Management}

Elsbach (2006:12) defines organisational perception management as "actions that are designed and carried out by organisational spokesperson to influence audiences' perceptions of the organisation." This means that organisational perception management can be defined as a set of tactics planned by the organisational spokesperson to alter the mental view held by parties with interests in the organisation. Four critical elements emerge from the definition, that is, perceptions of the organisation, actions, spokesperson(s) and audiences of the organisation. The interaction of these elements lead to a generally held perception of an organisation. 
Perceptions of the organisation are a combination of images, reputations and identities. In this context organisational perception is used interchangeably with image. Tactics employed by the organisation include verbal accounts, labels, business behaviour and physical markers. Spokespersons are representatives of the organisation who give information about the organisation to the audience. These include the leadership and specially designated employees of the organisation. The audience of the organisation includes internal (organisation's employees) and external (organisation's publics) audiences. An organisation does not exist in a vacuum but in a society where there are people who would view the organisation with different lens through which they view reality. However these views can be either negative or positive, whatever the people's views, these should be considered by the organisation.

Perception management is a concept that was largely used in the military and political leaders. Sun Tzu in Anderson and Engstrom (2009:1) propounds that,

The ability to subdue the enemy without any battle is the ultimate reflection of the most supreme strategy. The best strategy is to attack his relationships and alliances with other nations....[The most adept at warfare] will focus on using effective policies and strategies to keep all his resources intact and yet be able to contest for world supremacy against other states.

Sun Tzu affirms how statesman employ tactics that will shape the decisions of adversaries. Anderson and Engstrom (2009) describe the act of "shaping another' thoughts and actions" as perception management. According to the US Department of Defense in Jones (1999:2) perception management can be defined as,

Perception management involves all actions that convey and/or deny selected information and indicators to foreign audiences to influence their emotions, motives and objective reasoning; and to intelligence systems and leaders at all levels to influence official estimates, ultimately resulting in foreign behaviors and official actions favorable to the originator's objectives. In various ways, perception management combines truth projection, operations security [OPSEC] cover and deception, and psychological operations [PSYOP].”

The goals of perception management in the military are not the same as those that would apply in higher education institutions. In the military the ultimate goal is not to be viewed favorably but instill fear and dissuade adversaries from entertaining the thoughts of engaging them in a battle or war. While there are some elements not desirable (cover and deception, operations security, psychological operations) in this definition in the context of higher education institiutions, there are some which can be borrowed by HEIs such as influencing audiences through truth projection.

In Zimbabwe, perception management has not really been documented whether in the military or Higher Education Institutions. What has been seen to be taking the role of perception management is Public Relations which is present in all institutions of higher learning. This has been largely used through spokespersons. However, perception management also makes use of spokespersons. Perception management has been noted to be largely effective, before, during and after events that may threaten or enhance the image, reputation and identity of an organisation.

\subsection{Goals of Perception Management}

The ultimate goal of good images, reputations and identities is support and positive behaviour toward the organisation. Thus organisational perception management (OPM) is indispensible for higher and tertiary institutions (HEIs) to build good images, reputations and identities if they are to get private funding and high enrolment figures. Schlenker (1980) and Tedeschi (1981) identify two major goals of perception management as to deal with events that threaten and those that enhance the perception of the organisation. Ashforth \& Gibbs (1990) note that organisations seem more preoccupied with the image-threatening events than image-enhancing events perhaps because organisations are unwilling to take on the risks of protesting their legitimacy too much. it is clear from the literature that both events have to be managed for good images, reputations and identities. OPM is conducted to ensure that the image, reputation and identity of the organisation is as intended. OPM events are initiated and executed as a result of internal realization of its need by insiders due to the fact that the perception that the insiders have about themselves is consistent with the external audience. 
Events that might threaten HEIs image include among others immoral behaviour by the students, unfair labour practices, and poor quality product as have been leveled against HEIs in Zimbabwe. OPM would enable HEIs to correct and update the audience on the state of the matter rather than wait for time to heal the battered as explained by Elsbach and Sutton (1992). Events that enhance the images, reputations, or identities of an organisation should be put in place to ensure the maintanance of a good organisational reputation.

\subsection{Timing and Tactics of Organisational Perception Management}

Elsbach (2006) identifies three occasions when organisational perception management typically occurs: after organisational events, during organisational events, and before organisational events. These three occasions for perception management interact with the two reasons why perception management is needed to produce six categories of organisational perception management events. Figure 1 below demonstrates the interaction of the categories.

\begin{tabular}{|c|c|c|c|}
\hline Goals & $\begin{array}{c}\text { OPM After Organisational } \\
\text { Events }\end{array}$ & $\begin{array}{c}\text { OPM During } \\
\text { Organisational Events }\end{array}$ & $\begin{array}{c}\text { OPM Before } \\
\text { Organisational Events }\end{array}$ \\
\hline $\begin{array}{c}\text { Perception-Threatening } \\
\text { Events }\end{array}$ & $\begin{array}{c}\text { Remedial tactic Denial of } \\
\text { wrong doing and rational } \\
\text { symbolic behaviour }\end{array}$ & Communication Feedback & $\begin{array}{c}\text { Preemptive tactics, } \\
\text { rationalisation }\end{array}$ \\
\hline $\begin{array}{c}\text { Perception-Enhancing } \\
\text { Events }\end{array}$ & Informational cues & Reciprocity & $\begin{array}{c}\text { Selective release of } \\
\text { information }\end{array}$ \\
\hline
\end{tabular}

\subsection{After Organisational Events}

Most organisational perception management research focuses on the use of remedial tactics to repair, maintain, or enhance organisational images, identities, or reputations following either positive or negative events. This category includes organisational perception management after perceptionthreatening event such as scandals and product failures that threaten images of legitimacy, reputations for integrity, and identities related to status and distinctiveness. Benoit (1997, 1995) developed Benoit's Image Restoration Theory which supports Elsbach's tactics. The theory posits five primary macro strategies employed by organisations in their crisis communication: denial, evading of responsibility, reducing the offensiveness, corrective action, and mortification.

Denial, evading of responsibility and reducing offensiveness may involve justifications and consideration of concerns of the audiences. These may be used in scandals as questions are asked on the morality of top management if the scandal is linked to them. Benoit $(1997,1995)$ developed Benoit's Image Restoration Theory. The theory posits five primary macro strategies employed by organisations in their crisis communication: denial, evading of responsibility, reducing the offensiveness, corrective action, and mortification.

The organisation may emphasize distinctiveness other than those under attack Elsbach and Kramer (1996). The other alternative would be to highlight the organisation's affiliation with organisations that have suffered similar product failures but have continued to be highly ranked Thomsen and Rawson (1998).

This category also includes OPM following perception-enhancing events, such as university rankings, coming up with an innovation that solves a major national problem that may enhance the reputation of an organisation for quality and distinctiveness. Thus, after organisational events, organisations are required to provide informational cues that support their accounts or acclaims of the triggering event Bies, Shapiro and Cummings (1988), Dutton and Dukerich, (1991) and Elsbach, (1994). Following acclaim events the organisations do not only publicise their achievements as unique but as affirmation of reputations, exclusive categorization and distinctive identities Elsbach (2006). The acclaim events may be publicized on the "school web sites, in alumni magazines and in monthly business school newsletter" Elsbach (2006:140).

\subsection{During Organisational Events}

Controversies, such as contentious negotiations, which drag over some period call for OPM tactics during the events. Dynamism characterise the approaches as new information and audiences change. Ginzel et al. (1993:235) described evolving perception management as a "reciprocal influence process" between the audience and the organisation. The spokesperson gets feedback from the audience. Taking cognizance of the views of the audience, information gaps between the organisation 
and the audience are bridged. Lao Tzu the Chinese philosophy's saying holds true when he said "Knowing others is wisdom and knowing oneself is enlightenment." It is through feedback that the spokesperson gets to know about the audience and what their views towards the organisation are.

For instance, one university in Zimbabwe had a protracted battle with its academic staff, which was fired after taking part in a strike. The staff was dismissed and asked to vacate from the university houses. The staff did not release the accommodation and a legal battle ensued. The battle attracted new audience with each day as the media covered it while the institution did not respond nor conduct any visible OPM. Such a behaviour will lead to a prolonged outcome as the audience might not even know what transpired during the negotiations. This will result in the society holding negative views towards the university.

Elsbach (2006) identifies verbal accounts and categorizations as most commonly used tactics in such circumstances. Zbaracki(1998) observes that these allow the spokesperson to design messages that will address the multi-dimensional issues of the controversy as it may involve more than one issue and audience. In the above cited case there is the issue of dismissal and eviction issue. The audience being the affected staff, staff members not involved board members and the public at large. Symbolic behavior can also be employed where the organisation changes its mode of operation. Procedures may be changed to accommodate the concerns of the aggrieved parties.

\subsection{Before Organisational Events}

Some events are predicted with some accuracy that they will threaten the perception of the organisation. Events of this nature can be controlled by the organisation as to when and how they can be made public. In such instances anticipatory organisational perception management tactics are employed (Elsbach et al., 1998). Perception threatening events include anticipated negative performance reviews, introduction of controversial services or facilities. One state HEI faced perception challenges when it bid to take over a disused mining settlement facilities for its use. There was public outcry and concerns over the fate of the people occupying the houses in the settlement.

Preemptive tactics can be used by organisations as they have time to design messages to counter potential controversies. Anticipatory excuses, justifications and disclaimers can be effectively used to counter controversies Snyder et al (1983) and Hewitt and Stokes (1975). Excuses would be like the situation was beyond one's control or any other average person would have behaved in the same way anyway. For instance in the above cited case, justifications may be premised in economic interests of the country. Anticipated poor university rating would be bordered on the premise that the rating was flawed Snyder (1983). Press releases or media reports are made prior to the anticipated controversy Higgins and Snyder (1989). With the advent of a computer savor generation, posting on the net such information would be spread in all fronts.

OPM is also needed before anticipated, perception-enhancing events such as the anticipated achievement of a long-sought organisational or industry goal (e.g., getting ISO certification ) that may enhance the distinctiveness and status identities of an organisation. Pfeffer (1981) suggests that selective release of information may be used to influence organisational audience' perceptions. The tactic allows the organisation to plan when to release what information in what quantities and to whom.

\section{FINDINGS}

The findings of the study were presented in four themes, which were academics' knowledge, goals, timing and tactics of organisational perception management appropriate in higher education institutions.

\subsection{Academics' Knowledge of OPM}

Responding to the question, what do you understand by the term organisational perception management? Participants from various institutions were not aware of the term. A few argued that OPM was synonymous with public relations. Upon further inquiry on the elements of OPM academics showed understanding that, institutions had an image that needed to be protected through the actions of the spokesperson. Academics lacked knowledge of when OPM could be conducted. Asked whether their organisations conducted OPM activities, participants responded that they conducted public relations activities. 
The results show that academics are not aware of the term 'organisational perception management' possibly because it is a fairly new concept in organisational theory. The responses also show that OPM events are very sparse such that they are hardly noticeable by the internal audience. The OPM events are in the form of verbal, visual and or written message. These should have been noticed by academics as they are usually on the lookout for such messages during events that call for OPM.

\subsection{Academics Knowledge of Goals of OPM}

Academics had scanty ideas of the goals of OPM. The superior goal of organisational perception management was clear to the participants who responded that it is to save the image of the organisation. The participants understanding is in line with Benoit's (1995:71) view that the major though not the only goal of OPM is, "restoring or protecting one's reputation." They also responded that a good image for HEIs consequently leads to support from the private sector and high student enrolments as well as attracting highly qualified personnel.

\subsection{Academics Awareness of Timing and Tactics of OPM}

Responses to this question revealed that academics were generally aware of OPM events after perception threatening events and pointed out that these were necessary. One participant commented that silence by her university in the face of criticism on the moral behavior of its students is "unfortunate and damages the image of the institution. It would seem as if the institution does not see anything wrong with that kind of behavior." These findings confirm Rogers, Dillard, and Yuthas, (2005) and Trinkaus and Giacolone, (2005) view that in crisis management, silence impacts negative perception.

Participants indicated that the major tactics used after perception threatening events were giving information on the event or being silent about an event. One participant said, "In the labor issue, information on the innocence on the HEI was published in the press although most members of the public did not see the article." In the issue of students' moral behavior, one participant commented that the institution used the tactic of silence to deal with the issue. One participant suggested symbolic behavior where for example on the moral behavior of students, the institution, "condemns that kind of behavior. The institution may then set targets on the proposed date for completion of construction of halls of residence, so as to address the issue." This view concurs with Elsbach (2006:29) assertion that symbolic business behaviors are "business activities by an organisation or its members designed to affect audiences' perception of the organisation."

None of the participants was aware of OPM tactics used during and before perception threatening events. Asked on whether their organisations carried out OPM events in such circumstances they said they were not aware of any such events. Asked whether it was necessary for HEIs to perform OPM events during and before perception threatening events they said it was necessary so that the unintended perception does not become the reality. One participant noted that one institution that had two degree programmes and one diploma de-accredited by ZIMCHE, "was quiet during the negotiations and students kept on asking questions about the programme at regional level."

Asked whether there were perception-enhancing events that took place in their institutions participants confirmed such events had taken place. However, they said these had not been fully exploited to the advantage of institutions. One respondent pointed out that their Vice Chancellor had received several awards but the events were not heavily publicized in the press and the internet. This view confirms Rao (1994) in Elsbach (2006:135) observation that, "winning firms proclaimed their victories in their advertising campaigns." The respondent further said that these are some of the issues that need to be made noise about as they have a positive bearing on the image of the institution.

On the issue of prolonged perception-enhancing events participants showed that they appreciated the fact that such events also need to be managed. This can be done through the provision of information about the on-going programme. One institute was said to be in the process of applying for ISO 9001 certification but was not exploiting the event to its advantage. The institution could provide process information to both its internal and external audience to improve on its image, identity and reputation.

Participants indicated that before a perception-enhancing event occurs, institutions could set deadlines for the duration of such an event, as the construction of structures and give regular up-dates of the progress. Participants responded that they were not aware of perception-threatening events and as such had not experienced events of this nature in their institutions.

On suggestions for tactics that could be used to improve the perception of organisations participants proffered several ideas which were not identified earlier on. Participants pointed out that public 
relations should be proactive. They should not only surface when controversial issues arise otherwise their audience may not take them seriously. One participant said that, "information that addresses the needs of the organisation should be given soonest but most importantly avoid lying."

Participants identified physical markers such as putting-up own buildings, branding pens, carrying out practical researches that solve community problems and publicizing graduates. These findings confirm Elsbach (2006) assertion that the use of physical markers enhances the image, reputation and identity of the organisation. Some also identified the extensive use of technology in library operations as well as registration, teaching and publication of results.

Participants underlined the importance of communication with both internal and external audience although appropriate media was not mentioned. One participant noted that image building and protection could be enhanced through feedback from the audience.

\section{Conclusions}

From the results of the study the following conclusions were drawn;

- Academics do not have knowledge of Organisational perception management. The study also found that organisational perception management is a critical unit in institutions of higher learning as some respondents clearly pointed the need to have such a unit. Responses clearly highlighted the importance of OPM.

- Academics were aware of the goals of OPM from the background of Public Relations although they were not aware of the issues that OPM also entails perception enhancing and threatening events.

- Academics appreciated the view that perception enhancing events were very essential. The only tactic they were aware of was that of silence where an institution could simply be quiet about the negativities raised in the media. Some raised the issue that institutions only became active after image-threatening events would have occurred. Institutions were dormant before and during event threatening events.

- Overally, it can be concluded that OPM does have a position in HEIs as the existence of these institutions depends largely on issues to do with their images. As has been mentioned earlier on that enrolment and private funding are results of the institutional image, reputation and identity.

\section{RECOMMENDATIONS}

The study therefore recommends the following:

- Institutions should have awareness workshops on OPM so that employees participate effectively in image enhancing activities at shop flow level.

- Perception enhancing events in HEIs must be managed before, during and after their occurrence.

- These events should also make use of appropriate tactics which include informational cues, reciprocity and selective release of information.

- Institutions should avoid silence when perception threatening events occur. Such negative events should be addressed so that they do not wait for time to heal the battered image.

- Appropriate tactics should be used to address perception threatening events and these include reducing the offensiveness, corrective action, and mortification.

\section{REFERENCES}

Anderson, E.C. and Engstrom, J.G. (2009). China's use of perception management and strategic deception. SAIC

Ashforth, B. E., \& Gibbs, B. W. (1990). The double-edge of organisational legitimation. Organisational Science, 1, 177-194.

Bies, R. J., Shapiro, D. L., \& Cummings, L. L. (1988). Causal accounts and managing organisational conflict: Is it enough to say it's not my fault? Communications Research, $15,381-399$.

Dutton, J. E., \& Dukerich, J. M. (1991). Keeping an eye on the mirror: Image and identity in organisational adaptation. Academy of Management Journal, 34, 517-554. 
Elsbach, K. D. (1994). Managing organisational legitimacy in the California cattle industry: The construction and effectiveness of verbal accounts. Administrative Science Quarterly, 39, 5788.

Elsbach, K. D. (1999). An expanded model of organisational identification. In B. M. Staw \& R. I. Sutton (Eds.), Research in Organisational Behavior (Vol. 21, pp. 163-200). Stamford, CT: JAI

Elsbach, K. D., \& Sutton, R. I. (1992). Acquiring organisational legitimacy through illegitimate actions: A marriage of institutional and impression management theories. Academy of Management Journal, 35, 699-738.

Elsbach, K. D., Sutton, R. I., \& Principe, K. E. (1998). Averting expected controversies through anticipatory impression management: A study of hospital billing. Organisation Science, 9, 68-86.

Ginzel, L. E., Kramer, R. M., \& Sutton, R. I. (1993). Organisational impression management as a reciprocal influence process: The neglected role of the organisational audience. In L. L. Cummings \& B. M. Staw (Eds.), Research in organisational behavior (Vol. 15, pp. 227-266). Greenwich, CT: JAI.

Hearit, K. M. (1994). Apologies and public relations crisis at Chrysler, Toshiba, and Volvo. Public Relations Review, 20, 113-125.

Hewitt, J. P., \& Stokes, R. (1975). Disclaimers. American Sociological Review, 40, 1-11.

Higgins, R. L., \& Snyder, C., R. (1989). The business of excuses. In R. A. Gracalone \& P. Jones,C.S. (1999). Perception management process, Military review Dec 1998-Feb 1999 pp. 38-43.

Rosenfeld (Eds.), Impression management in the organisation (pp. 73-86). Hillsdale, NJ: Lawrence Erlbaum Associates.

Pfeffer, J. (1981). Management as symbolic action: The creation and maintenance of organisational paradigms. In L. L. Cummings \& B. M. Staw (Eds.), Research in organisational behavior (Vol. 3, pp. 1-52). Greenwich, CT: JAI.

Schlenker, B. R. (1980). Impression management: The self-concept, social identity, and interpersonal relations. Monterey, CA: Brooks/Cole.

Snyder, C. R., Higgins, R., \& Stucky, R. J. (1983). Excuses. Masquerades in Search of Grace. New York: John Wiley \& Sons.

Tedeschi, J. T. (Ed.). (1981). Impression management theory and social psychological research. New York: Academic Press

Thomsen, S. R., \& Rawson, B. (1998). Purifying a tainted corporate image: Odwalla's response to an E. Coli poisoning. Public Relations Quarterly, 43, 35-46.

Zbaracki, M. J. (1998). The rhetoric and reality of total quality management. Administrative Science Quarterly, 43, 602-636.

http://www.theeye.co.zw 13 September 2013

\section{AUTHORS BiograPHY}

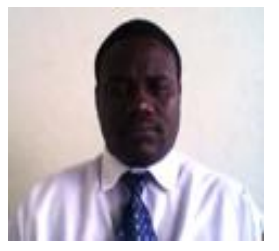

MR. TRUST NYENYA, is the Regional Quality Assurance Coordinator for ZOU's Mashonaland East Region. He is an educationist and academic with vast experience spanning over twenty years in all sectors of the education from primary education to higher education. He holds a Certificate in Education (UZ), Bachelor of Education in Educational Administration, Planning and Policy Studies (ZOU) and Master of Business Administration (ZOU). He has published research articles in education and quality assurance. He is a DPhil student working on a thesis in quality assurance. His research interest is in quality assurance and educational assessment and human resources.

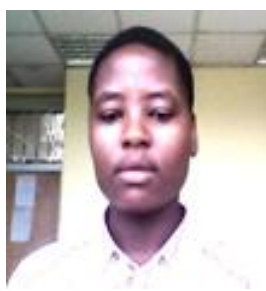

MS SARAH YEUKAI MUKUNGURUTSE, is the Regional Programme Coordinator and Lecturer in the Department of Languages and Literature at the Zimbabwe Open University in Mashonaland East Region. She holds a BA Honors' in English Degree from the University of Zimbabwe as well as a Masters in English Degree from the University of Zimbabwe. She is keen in publishing articles in education as well as in arts. 